\title{
3.9. Mugikorren erabileraren arriskuak
}

\author{
Rakel Gamito Gomez \\ EHUko Hezkuntza eta Kirol Fakultateko irakasle eta ikerlea \\ rakelgamito@gmail.com
}

\section{Sarrera}

1983an aurkeztu eta 1984ko martxoaren 13an jarri zen salgai lehenengo telefono mugikor komertziala: Motorola DynaTAC 8000x-a. 800 gramo pisatzen zituen eta, argazkian (1. irudia) ikus daitekeen bezala, ez zen txikia $(33 \mathrm{~cm}$ x 4,5 cm x 8,9 cm). Ordubetez inolako espazio fisikori lotuta egon gabe telefonoz hitz egiteko aukera eskaintzen zuen. Bere prezioa 3995 \$koa zen arren, urtebetean 300.000 unitate saldu ziren eta estatus sozialaren ikur bilakatu zen.

1. irudia: Martin Cooper, Motorola DynaTAC 800x-aren sortzailea, lehenengo telefono mugikor komertziala erabiltzen. Iturria: http://www.wikipedia.org.

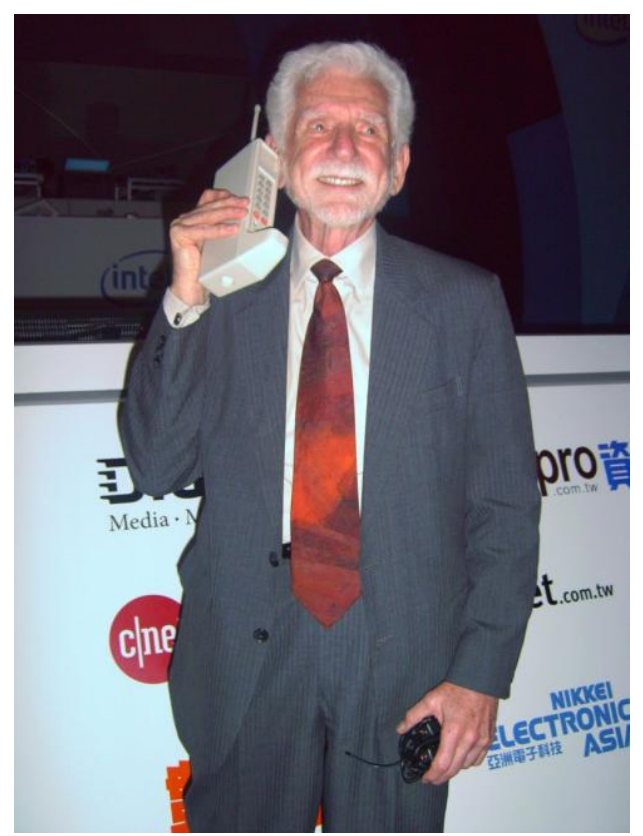

Motorola DynaTAC 8000x-a gaur egun inguruan ditugun telefono mugikorrekin alderatuz gero, erraz antzematen da azken 30 urteetan teknologia digitalak jasan duen garapen azkarra. Gainera, bestelako tresna eramangarrien eta Internet sarearen aurrerapenak nabarmenak izan dira.

Era berean, garapenak gailu digitalen hedapena ekarri du. 2019an, Euskal Autonomia Erkidegoko (EAE) 16 eta 74 urte bitarteko biztanleriaren \% 86,8k telefono mugikorra zuen, 
eta etxetik kanpo Internetera konektatzeko erabili zuen (INE, 2019). Konexioaren helburuak askotarikoak dira: lan egin, berriak irakurri, online erosi, sare sozialak erabili, etab.

Alegia, azken urteotako garapenak ukaezinak diren aldaketa soziologikoak eragin ditu. Urte gutxitan, pantailak eta online aplikazioak jendartearen ingurune natural bilakatu dira, lan, aisialdi eta harremanen oinarri.

\section{Haurrak, nerabeak eta gailu digitalak: ondo zaindu beharreko harreman sendoa}

Adin txikikoak aro digitalean jaio dira, eta gailu digitalak zein Internet konexioa euren egunekotasunaren bizkarrezur dira. EAEko 10 eta 15 urte bitarteko gazteen \% 95,8k Internet erabiltzen du, eta \% 73,1ak dagoeneko telefono mugikor propioa dauka (INE, 2019).

Gainera, urtez urte, Interneten lehenengo aldiz sartzen direnen adina jatsi egiten da (momentu honetan, batez besteko adina 7 urtekoa da), eta haurrek zein nerabeek egunero gailu digitalei eskaintzen dieten denborak gora egiten du (Gamito, 2019). Erabileraren helburua batik bat aisialdia izan ohi da: jolastu (online), bideoak ikusi (YouTube-n eta TikToken) eta berdinen artean komunikatu (WhatsApp edo Instagram bidez).

Zalantzarik gabe, konektibitateak aukera eta abantaila ugari eskaintzen dizkio jendartearen sektore gazteenari, baina teknologia ez da neutroa eta bizipen gatazkatsuen iturri izan daiteke. Pantailetan ere erasoak ohikoak dira (Gamito, Aristizabal, Vizcarra eta Tresserras, 2017):

- Ziberjazarpena: berdinen arteko jazarpen jarraitua (irain-mezuak, mehatxuak, zurrumurruak edota eszena iraingarriak zabaltzea, identitatea ordezkatzea, bazterketa...), gailu digitalen bitartez (Garaigordobil, 2011).

- Sextorsion-a: sexu izaerako mezu edota eduki intimoak zabaltzea (bereziki argazki edo bideo sexualak), baimenik gabe eta mina egiteko asmoz (Klettke, Hallford eta Mellor, 2014).

- Grooming-a: adin txikiko baten aurka sexu-jazarpena bideratzeko asmoz (irudi erotikoak lortu, sexu-harremanak izan...), pertsona heldu batek erabiltzen dituen estrategiak: adinaz eta sexuari buruz gezurra esatea, lotura emozionalak finkatzea, datu pertsonalak lortzea, etab. Horrela, adin txikikoak lagun birtualaren sexu-helburuak onartzen ditu, lagunen arteko mesede boluntario gisa (UNICEF, 2017).

- Eduki ezegokiak: indarkeria, terrorismoa, pornografia, drogak, armak, ohitura ez-osasungarriak (elikadura-desordenak adibidez), arrazakeria, xenofobia, sektak, kontsumismoa, etab. Oso erraza gerta daiteke eduki ezegokiekin topo egitea (Gil-Juliá, Castro-Calvo, Ruiz-Palomino, García-Barba eta Ballester-Arnal, 2018).

- Gehiegizko edota neurririk gabeko erabilera: etengabe konektatuta egoteko premia, bizitza-kalitatean eragin negatiboa duena, harremanak eta bestelako jarduerak (eskolako lanak, ariketa fisikoa, atsedena...) alde batera uztea ondorio duelako (Ruiz-Palomero, Sánchez-Rodríguez eta Trujillo-Torres, 2016).

Orain arte zerrendatutako arriskuez gain, testuinguru digitalean elkarlotuta dauden beste bi kontzeptu izan behar dira kontuan: pribatutasuna eta nortasun digitala. Gaur egun, Internet 
pertsonen bizitzaren eta nortasunaren erakusleiho erraldoi bilakatu da, agerraldi eta elkarrekintza bakoitzak aztarna digitala uzten duelako.

Adin txikikoen kasuan, belaunaldi gardenaren parte dira (Sabater, 2014), euren bizitza pertsonalari buruzko gai eta datu anitz etengabe argitaratzen baitituzte. Praktika horren helburua da online bizitza sozialaren kide eta berdinen artean onartuak sentitzea. Horregatik, jasotzen dituzten like (atsegin dut) kopurua garrantzi handikoa da (Sherman, Payton, Hernandez, Greenfield eta Dapretto, 2016).

Beraz, online jarduera kudeatzea konplexua izan daiteke. Teknologiak haur eta nerabeen sozializazioan eragin zuzena duenez, zerrendatutako egoera gatazkatsuek euren harremanak, nortasuna eta osasuna (ongizate fisikoa zein psikologikoa) gogorki kaltetu ditzakete eta epe luzerako ondorio larriak ekarri. Interneten eta gailu digitalen erabilera ezegokiak haserrea, estresa, antsietatea, bakardadea, depresioa, nahaste fisikoak edota autoestimuaren galera eragin ditzake eta, kasurik larrienean, suizidioarekin lotutako pentsamenduak sortu (Bilgrami, McLaughlin, Milanaik eta Adesman, 2017).

Horregatik, premia handikoa da adin txikikoen alfabetatze digitala zein mediatikoa bermatzea. Egungo gazteek teknologia modu autonomoan eta seguruan erabiltzen ikasi behar dute, jarrera osasuntsua garatzeko, sortu daitezkeen gatazkei aurre egiteko estrategiak eskuratzeko eta, horrela, online bizikidetza positiboa sustatzeko.

Euskal Herriko Ikastolek (Ikastolen Elkarteak) erronkari erantzun nahi izan diote, eta Lehen Hezkuntzako 5. eta 6 . mailako ikasleei burujabetza digitala bere osotasunean lantzeko aukera eskaini. Horretarako, IKT on hezkuntza-aholkularitzaren parte-hartzearekin batera, hezkuntza-komunitate osoa inplikatzen duen \#lzandig proiektua garatu eta martxan jarri da, helburu nagusi honekin: Interneten eta mugikorraren erabilera arduratsua sustatzea, pribatutasuna, nortasun digitala edota online parte-hartze publikoa bizitzarako gaitasun gisa ulertuta.

\section{2. \#lzandig: segurtasun digitalerako proiektu integrala (Euskal Herriko Ikastolak eta IKT on)}

\subsection{Helburuak}

\#lzandig proiektuaren helburu orokorra konpetentzia digitalaren segurtasunaren atala lantzea da, gai horretan inplikazio erreala lortzeko. Hortaz, helburu zehatz hauei jarraitzen die:

- Hezkuntza-komunitate osoan, eta bereziki ikasleengan, segurtasun digitalarekiko jarrera aktiboa sustatzea.

- Irakasleekin batera, gelan konpetentzia digitalaren segurtasunaren atala lantzeko aukerak garatzea.

- Familien kezkak azaldu eta etxean ere bidelagun digitala izateko gidalerroak eskaintzea.

- Ikastolen artean ikasitakoa komunean jartzeko gunea sortzea. 


\subsection{Ardatzak eta dinamikak}

Horretarako, proiektuak lau ardatz, foro edo parte-hartzaile ditu: ikasleak, irakasleak, familiak eta topaketa.

- Ikasleak: Interneten eta gailu digitalen erabilera arduratsua lantzea (arriskuak, nortasun digitala eta pribatutasuna), txokotan banatuta.

- Parte-hartzaileak: Lehen Hezkuntzako 5. eta 6. mailako ikasleak.

○ Iraupena: 3,5 ordu (goiz oso bat).

○ Edukiak:

- Interneten arriskuak eta haien aurrean izan beharreko jarrera kritikoa.

- Pribatutasuna zaintzearen garrantzia.

- Like-ak: zer dira eta zertarako behar ditugu?

- Ezarpenak: sare sozial nagusienen pribatutasun-aukerak.

- Irakasleak: gelan segurtasun digitala lantzen jarraitzeko lan-saioa.

- Parte-hartzaileak: Lehen Hezkuntzako 3. mailatik Derrigorrezko Bigarren Hezkuntzako 2. mailara arteko irakasleak.

- Iraupena: 2 ordu.

○ Edukiak:

- Ikasleekin egindako lanketa eta haren ondorioak.

- Topaketaren helburua.

- Segurtasun digitala tutoretza-saioetan lantzeko aukerak.

- Online ikastaroa.

- Familiak: egoeraren eta proiektuaren berri izateko hitzaldia.

- Parte-hartzaileak: gaian interesa duten familiak.

O Iraupena: 1,5 ordu.

- Edukiak:

- Haur eta gazteen errealitate digitala: erabilera eta arriskuak.

- Proiektua: ikasleen saioak.

- Prebentzio-gidalerroak.

- Topaketa: ikasitakoa partekatzeko eta segurtasun digitalari buruzko mezuak barneratzeko gunea.

○ Parte-hartzaileak: proiektuan parte hartu duten ikasleak eta irakasleak.

O Iraupena: 3,5 ordu (goiz oso bat).

○ Edukiak:

- Helduei (irakasleei eta familiei) zuzendutako mezuak.

- Interneten eta gailu digitalen erabilera arduratsua bermatzeko, ikasleek hartzen dituzten konpromisoak. 


\subsection{Balidazioa, fase pilotua eta lehenengo ikasturtea}

2018/19 ikasturtean, IKT on hezkuntza-aholkularitzak \#Izandig proiektua diseinatu zuen, eta, momentu oro, proposamenaren egokitasuna Euskal Herriko Ikastolen (Ikastolen Elkarteko) arduradun eta teknikariekin egiaztatu zen. Gainera, martxoan, hainbat ikastolatako zuzendari eta IKT arduradunekin batera balidazio-saio bat egin zen. Bertan, proiektuaren beharrari buruz hausnartu, plangintza aurkeztu eta hobetze-proposamenak jaso ziren.

Proiektuaren esperimentazio-fasea edota fase pilotua 2019ko maiatza eta ekaina bitartean jarri zen martxan: ikasleekin, irakasleekin eta familiekin saioak, maiatzean; eta topaketa, ekainean. Lau ikastolek hartu zuten parte (Bizkaia: 1, Gipuzkoa: 2, Nafarroa: 1); guztira, Lehen Hezkuntzako 149 ikasle. Hobetu beharreko zenbait alderdi identifikatu ziren arren, balorazio orokorra oso positiboa izan zen, eta, batez ere, ikasleek gaiarekiko adierazitako interesa, inplikazioa eta hitz egiteko beharra azpimarratu ziren.

Aurten (2019/20 ikasturtea), proiektua bere osotasunean martxan jarri da, eta parte-hartze erabat arrakastatsua izan du. Oraingoan, ikastolen kopurua kontuan izanda, bi txanda egitea erabaki da. Lehenengoan, zortzi ikastolek hartu dute parte (Bizkaia: 2, Gipuzkoa: 3, Araba: 2, Nafarroa: 1); guztira, 588 ikasle. Ikasleekin, irakasleekin eta familiekin saioak 2019ko iraila eta urria bitartean egin dira eta topaketak (bi topaketa egin dira eta bakoitzean hiru ikastolek hartu dute parte), azaroan eta abenduan. Bigarren txandan, hamaika ikastolek hartu dute parte (Bizkaia: 3, Gipuzkoa: 7, Nafarroa: 1); guztira Lehen Hezkuntzako 5. eta 6. mailako 1.042 ikasle. Ikasleekin, irakasleekin eta familiekin saioak 2020ko urtarrila eta otsaila bitartean egin dira; topaketak, aldiz, maiatzean egitea aurreikusten da.

Ikasleen kasuan, alde handiak antzeman dira mailaren eta ikasturte garaiaren arabera. Alegia, kontzeptuak ez dira modu berean lantzen irailean 5. mailan hasten direnekin edota maiatzean 6. maila amaitzen dutenekin, tarte horretan online bizipenak izugarri aldatzen direlako. Orokorrean, ikasleek arriskuak ezagutzen dituzte, baina praktika ez seguruak oso ohikoak dira euren artean. Horregatik, txikitatik erabilera arduratsurako kontzientzia kritikoa lantzea behar-beharrezkoa da.

Irakasleen eta familien kasuan, gaiarekiko ardura nabarmena da. Testuinguru digitalaren abiaduragatik kezkatuta daude; eta, zenbait kasutan, beldurtuta, segurtasun digitalaren arloan duten ezagutza edota prestakuntza-maila eskasa dela uste dutelako. Helduen artean erabilera arduratsuari buruzko kontzientzia piztearen beharra azpimarratzen da, eskolaren eta familien hezkuntza-zeregina eta inplikazioa bermatze aldera.

Topaketetan proiektuaren norabide onaren ebidentziak jaso dira. Ikasleek ingurune digitalen erabilera arduratsurako ezinbestekoak diren irizpideak barneratu dituzte, eta segurtasun digitala bermatzeko jarraibideak oso modu sortzailean jaso eta adierazi. Gainera, informazio pertsonala zaindu, ezezagunekin argi ibili eta gainerako erabiltzaileak errespetatu zein laguntzeko konpromisoa hartu dute.

Bestalde, irakasleei eta familiei zuzendutako eskariak edota mezuak oso argiak dira: haur eta nerabeen argazkiak argitaratu aurretik (sare sozialetan edota profiletako argazki modura), eskatu baimena; eskaini arriskuei eta pribatutasunari buruzko informazioa eta utzi tarteka mugikorra aldera batera. 


\subsection{Etorkizuna}

Badirudi jendartean adin txikikoen gaitasun digitalari buruzko kezka zabaldu dela; horren isla da hezkuntza-zentro eta eragile ugarik gaiari buruz adierazitako interesa. Horri erantzuteko, Euskal Herriko Ikastolek (Ikastolen Elkarteak) eta IKT on-ek lanean jarraituko dute. Asmoa da hemen deskribatzen den proiektuari jarraikortasuna ematea eta, agian, Derrigorrezko Bigarren Hezkuntzan beste lanketa mota batekin osatzea. Digitalizazioaren abiadura ikaragarrizkoa da; baina mugitzen ari gara, ahal den neurrian harrapa ez gaitzan!

Premiazkoa da adin txikikoek Interneten eta gailu digitalen (mugikorra barne) erabilera arduratsua garatzea, lehenbailehen. Horretarako, hezkuntza-agenteek gaitasun kritikoa oinarri duen lanketa praktikoa eskaini behar diete ikasleei. Informazioa eta hausnarketa dira kontzientzia pizteko eta prebentzioa bermatzeko bide bakarrak.

\section{Bibliografia}

1. Bilgrami, Z., McLaughlin, L., Milanaik, R. eta Adesman, A. (2017). Health implications of newage technologies: a systematic review. Minerva pediatrica, 69(4), 348-367. https://doi.org/10.23736/S0026-4946.17.04937-4

2. Gamito, R. (2019). Adin txikikoen Interneten erabilerari eta arriskuei buruzko kasu azterketa bat. Pertzepziotik kontzientzia piztera [Doktore-tesia]. Universidad del País Vasco/Euskal Herriko Unibertsitatea (UPV/EHU), Vitoria-Gasteiz. https://addi.ehu.es/handle/10810/35445?locale-attribute=es

3. Gamito, R., Aristizabal, P., Vizcarra, M. T. eta Tresserras, A. (2017). La relevancia de uso crítico y seguro de internet en el ámbito escolar como clave para fortalecer la competencia digital. Fonseca, 15, 11-25. https://doi.org/10.14201/fic2017151125

4. Garaigordobil, M. (2011). Prevalencia y consecuencias del cyberbullying: una revisión. International Journal of Psychology and Psychological Therapy, 11(2), 233-254. https://www.redalyc.org/articulo.oa?id=56019292003

5. Gil-Juliá, B., Castro-Calvo, J., Ruiz-Palomino, E., García-Barba, M. eta Ballester-Arnal, R. (2018). Consecuencias de la exposición involuntaria a material sexual en adolescentes. International Journal of Developmental and Educational Psychology (INFAD), 2(1), 33-44. https://doi.org/10.17060/ijodaep.2018.n1.v2.1159

6. INE, Instituto Nacional de Estadística (2019). Encuesta sobre equipamiento y uso de las tecnologías de la información y comunicación en los hogares. Resultados año 2019. https://www.ine.es/dyngs/INEbase/es/operacion.htm?c=Estadistica C\&cid=1254736176741\&menu=resultados\&idp=1254735576692

7. Klettke, B., Hallford, D. J. eta Mellor, D. J. (2014). Sexting prevalence and correlates: A systematic literature review. Clinical Psychology Review, 34(1), 44-53. https://doi.org/10.1016/j.cpr.2013.10.007

8. Ruiz-Palomero, J., Sánchez-Rodríguez, J. eta Trujillo-Torres, J. M. (2016). Utilización de Internet y dependencia a teléfonos móviles en adolescentes. Revista Latinoamericana de ciencias sociales. Niñez y Juventud, 14(2), 1357-1369. https://doi.org/10.11600/1692715x.14232080715

9. Sabater, C. (2014). La vida privada en la sociedad digital. La exposición pública de los jóvenes en internet. Aposta. Revista de ciencias sociales, 61, 1-32. http://www.apostadigital.com/revistav3/hemeroteca/csabater.pdf

10. Sherman, L. E., Payton, A. A., Hernandez, L. M., Greenfield, P. M. eta Dapretto, M. (2016). The power of the Like in Adolescence: Effects of Peer Influence on Neural and Behavioral Responses to Social Media. Psychological Science, 27(7), 1027-1035. https://doi.org/10.1177/0956797616645673

11. UNICEF (2017). Guía de sensibilización sobre Convivencia Digital. Buenos Aires: Fondo de las Naciones Unidas para la Infancia (UNICEF). https://www.unicef.org/argentina/sites/unicef.org.argentina/files/2018-04/COM-Guia_ConvivenciaDigital_ABRIL2017.pdf 